\title{
Predictors of Successful Weight Loss Maintenance: A Qualitative Comparative Analysis
}

\author{
Mary E. Baugh1, Jyoti Savla², Jeremy D. Akers³, Hollie A. Raynor4, Kevin P. Davy1, \\ Brenda M. Davy ${ }^{*}$ \\ ${ }^{1}$ Department of Human Nutrition, Foods and Exercise, Virginia Tech, Blacksburg, USA \\ ${ }^{2}$ Center for Gerontology and Department of Human Development, Virginia Tech, Blacksburg, USA \\ ${ }^{3}$ Department of Health Sciences, James Madison University, Harrisonburg, USA \\ ${ }^{4}$ Department of Nutrition, University of Tennessee at Knoxville, Knoxville, USA \\ Email: bdavy@vt.edu
}

Received 25 February 2014; revised 5 April 2014; accepted 25 April 2014

Copyright (C) 2014 by authors and Scientific Research Publishing Inc.

This work is licensed under the Creative Commons Attribution International License (CC BY). http://creativecommons.org/licenses/by/4.0/

c) (i) Open Access

\begin{abstract}
Individuals successful at weight loss maintenance (WTLM) utilize similar behaviors but in varying amounts and combinations. Research identifying characteristics which predict WTLM success could be used to develop effective WTLM treatment programs. The purpose of this retrospective analysis was to determine behavioral (e.g., self monitoring of dietary intake) and biological factors (e.g., sex) which may influence WTLM success. Methods: In a previously conducted 12-month WTLM study, weight-reduced middle-aged and older men and women $(n=39)$ were assigned behavioral goals and asked to daily self-monitor body weight, fruit and vegetable intake, water consumption, and physical activity. This investigation utilized a crisp set qualitative comparative analysis (QCA) to characterize individuals' weight changes and behaviors. Sex difference in clinically significant weight loss (WL) $(\geq 5 \%$ WL) at 12 months was investigated, and growth curve models estimated interaction effects between sex and WTLM predictors. Results: QCA findings suggest patterns of weight change during the initial three months of WTLM treatment may dictate 12-month weight outcomes. No sex difference was found in clinically significant WL or in the interaction of sex and behaviors on weight change. Conclusions: WTLM treatments should provide more intensive support during transition from WL to WTLM, particularly during the first three months.
\end{abstract}

\section{Keywords}

Weight Loss Maintenance, Obesity, Sex Differences, Behaviors, Predictors

${ }^{*}$ Corresponding author. 


\section{Introduction}

Obesity and related diseases place a huge financial burden on the country, costing approximately $10 \%$ of total medical spending in 2008 [1]. Weight loss (WL) attempts, particularly utilizing behavioral lifestyle methods, are largely successful [2]; however, maintaining WL is challenging for most people, and relapse is common [3] [4]. The majority of those successful at WL regain all lost weight within 3 - 5 years after treatment [5]-[7]. The likelihood of continued success increases for those who are able to maintain their initial WL for $\geq 2$ years [8] [9]. Identifying practical, sustainable solutions for effective WL and weight loss maintenance (WTLM) that can be implemented at the clinical practitioner level are essential [4] [10].

Changing lifestyle behaviors remains at the forefront of effective WTLM treatment strategies. Self-monitoring of body weight, physical activity, and fruit and vegetable consumption are effective WTLM behaviors [11] [12], and increasing water intake may be an important strategy as well [13] [14]. However, individuals successful at WTLM implement behavior changes in varying amounts and combinations [15]. Weight loss in response to habitual physical activity and dietary intake exhibits a wide inter-individual variability, and thus, despite similar amounts of physical activity or patterns of dietary intake, some individuals may not achieve successful WTLM [16]. This individual variability in behavior implementation and weight change responses has led researchers to attempt to identify specific predictors of successful WTLM in order to develop more effective WTLM strategies.

Behavioral and physiological evidences suggest that sex may be an important predictor of WTLM success. A long-standing notion that men are more successful at WL and WTLM with less effort than women exists among the general public and practitioners [17], but because men are typically underrepresented in behavioral interventions, research comparing sex differences in WTLM is sparse [18] [19]. Physiological evidence suggests that women experience a compensatory increase in energy intake in response to physical activity, which may thwart efforts to maintain WL through physical activity, whereas men do not [20] [21]. Other research indicates that men more accurately regulate energy intake in an acute ad libitum meal after a calorie-containing preload [22]. Because many physiological functions influence behavioral processes [23], men and women likely approach WTLM with differing behaviors. Through structural equation modeling, Wang et al. found that though men and women have a similar mediator (i.e., attention to weight and health habits) in predicting health behavior outcomes (i.e., eating behavior, eating out behavior, and physical activity), the moderating effect of predictors on the relationship between the mediator and health behavior outcomes is more complex for women than for men [24].

Within this context, the overall purpose of this investigation was to observe the occurrences of weight relapse (i.e., $\geq 3 \mathrm{lb}$ weight gain) and describe behavior changes in response to weight change. Additional objectives were to determine if sex differences exist in maintenance of clinically significant WL and to determine if there were differences in the interaction of sex and WTLM behaviors, specifically in reported fruit and vegetable intake and physical activity.

\section{Methods}

\subsection{Subjects and Design}

This investigation was a retrospective analysis of data collected from two previously conducted intervention trials of WL and WTLM, the details of which have been described previously [25] [26]. Study protocols for both intervention trials were approved by the Virginia Tech Institutional Review Board, and all participants provided written informed consent prior to enrollment in the studies [25] [26]. Briefly, individuals aged 55 - 75 years were invited to participate in a single-blind randomized controlled trial, led by a registered dietitian, in which they were assigned to one of two WL groups for 12 weeks: a) 1200 to 1500 kcal hypocaloric diet or b) 1200 to $1500 \mathrm{kcal}$ hypocaloric diet $+16 \mathrm{fl} \mathrm{oz}$ water prior to each main meal [25]. Because the number of obese middle-aged and older adults has increased in recent years, addressing strategies for WL and WTLM in this population is warranted [26]. Following the WL trial, participants were invited to enroll in the WTLM trial [26]. Of the 42 individuals who completed the WL trial, 39 completed the WTLM trial [26]. Individuals continued within their WL trial randomization group (i.e., $16 \mathrm{fl}$ oz water preload or no water preload) but without caloric restriction and were asked to self-monitor their daily body weight, physical activity (measured by pedometer step count), and fruit and vegetable intake (measured by servings). Participants in the water preload group were 
asked to also self-monitor their water consumption [26]. All participants were provided tracking sheets to record their daily behaviors and were asked to return tracking sheets weekly to the study coordinator [26]. Overall program goals for all participants were to maintain their reduced body weight (within 3 lbs of their laboratorymeasured baseline body weight), achieve 10,000 or more steps per day, consume at least 5 servings of fruits and vegetables daily, and, for the water preload group only, consume at least $48 \mathrm{fl} \mathrm{oz}$ of water each day [26]. Participants were considered compliant with returning tracking sheets regardless of accuracy or completeness. Body weight, blood pressure, and four day food records were assessed monthly in the laboratory. Body composition (DXA) (GE Lunar Prodigy; GE Healthcare, Madison, WI) and resting metabolic rate (RMR) via indirect calorimetry (Parvo Medics TruOne 2400, Sandy, UT) were evaluated at baseline, 6, and 12 months of WTLM [26]. For the purposes of this post hoc analysis, groups were primarily distinguished by sex, rather than the original randomization to water preload or no water preload groups, although original group assignment was included in the statistical and qualitative analyses. Successful WTLM was defined as remaining below or within 3 lbs of baseline-measured body weight.

\subsection{Qualitative Analysis: Predictors of Weight Loss Maintenance Success}

Single missing values for daily body weights were replaced using the mean of nearby points in the Statistical Package for the Social Sciences software (SPSS, version 20.0 for Windows, 2011, SPSS Inc., Chicago, IL), and missing daily values for behaviors (physical activity, fruit and vegetable intake, and water consumption) were imputed using the expectation-maximization algorithm. The expectation-maximization method first determines a conditional expectation for a missing value based on observed values and then uses maximum likelihood estimates of parameters to find the most likely value [27]. Because of the high daily variance of behavioral data, in contrast to the relatively consistent daily body weight measurements, the expectation-maximization algorithm was used rather than calculating the mean of surrounding data points. Once missing values were replaced, weekly averages of body weight, exercise, fruit and vegetable intake, and water consumption (for the water preload group only) were calculated. Graphs illustrating changes in weekly averages of these variables for each participant were generated.

The 39 individual graphs were then categorized based on weight outcomes (i.e., successful or unsuccessful, in terms of a $3 \mathrm{lb}$ regain). Participants were characterized using the following four discrete weight change categories: WL $(n=13)$, weight stable $(n=7)$, relapse with recovery $(n=9)$, and relapse without recovery $(n=10)$. WL participants were defined as those who lost weight over the course of the 12-month period and whose average final week remained $\geq 3 \mathrm{lbs}$ below baseline weight. Weight stable participants remained within $3 \mathrm{lbs}$ of baseline weight and never exceeded a $3 \mathrm{lb}$ gain from baseline. Those in the relapse with recovery group gained $\geq 3$ lbs more than baseline body weight at least once during the study period but recovered to within 3 lbs of baseline weight by the final week's average weight. The relapse without recovery group consisted of individuals who gained $\geq 3 \mathrm{lbs}$ more than baseline weight at least once during the study period and remained $\geq 3 \mathrm{lbs}$ above baseline weight during the final week. Figure 1 depicts examples of individual graphs for each of the four weight outcome groups.

Once graphs were categorized, three researchers then independently reviewed individual graphs within each category and discussed observations. Individuals who were noncompliant in returning tracking sheets for weeks 45 - 52 consecutively were excluded from further analysis $(n=10)$ based on the reasoning that imputed average weights and behaviors for the final weeks could potentially categorize an individual incorrectly. Individual characteristics related to weight and behavior change were assessed and observations were discussed among researchers.

Based on these general observations, a crisp set qualitative comparative analysis (QCA) was used to determine behavioral conditions and factors required for the desired outcome (i.e., successful WTLM) to occur. QCA is a tool used in exploratory evaluation to probe for potential preliminary information with combined qualitative and quantitative techniques [28]. In this type of analysis, conditions potentially associated with a given outcome are calibrated in a dichotomous manner to identify multiple causations of an outcome while still maintaining the heterogeneity of individual characteristics [28]. Conditions deemed "necessary" are present in all successful categories but may also be present in unsuccessful ones, and "sufficient" conditions or combinations of conditions are present only in successful categories and must be present for the desired outcome to occur [28]. For the QCA, researchers determined a list of potentially causal conditions and defined decision rules for each condition. 

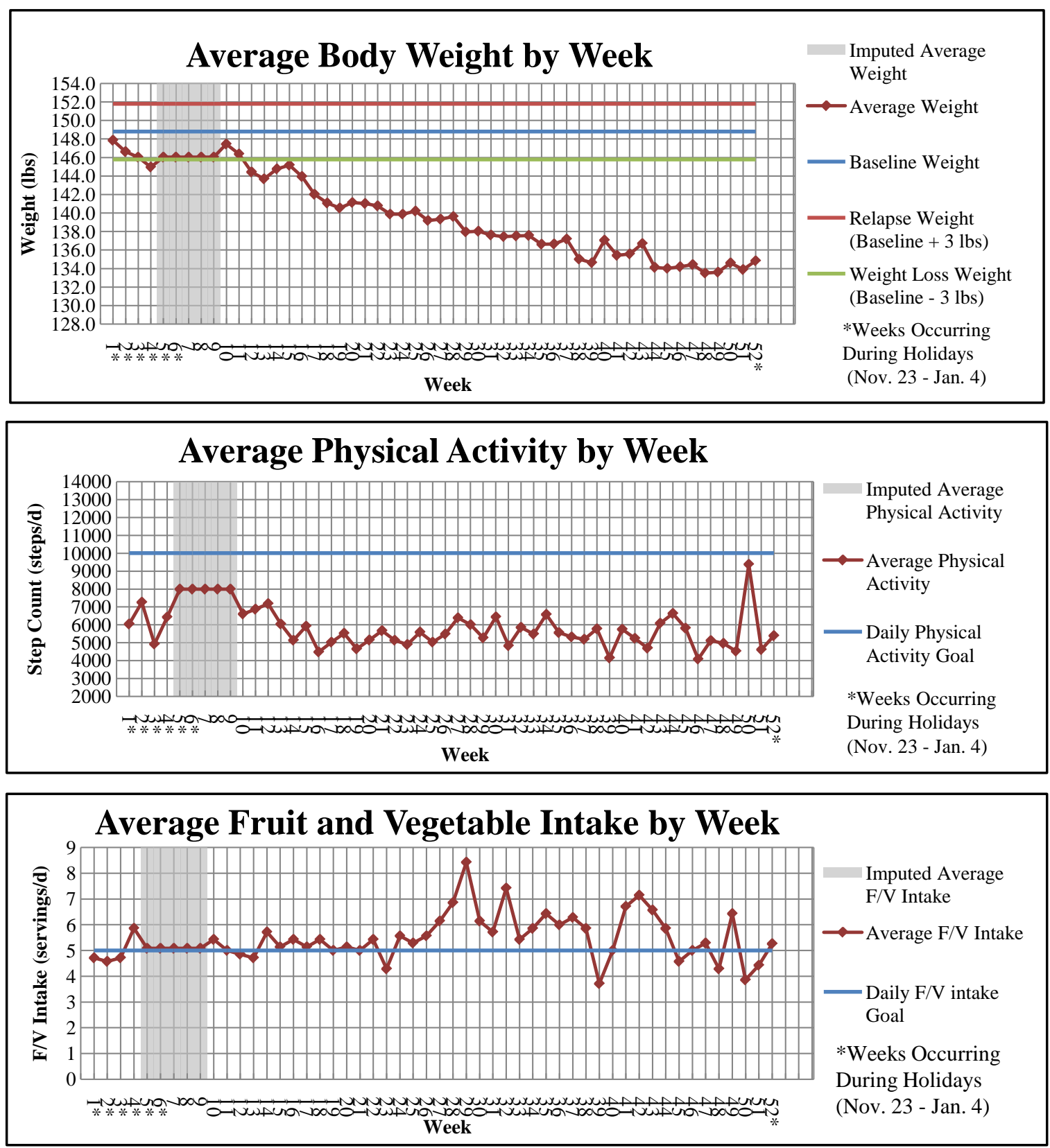

(a)

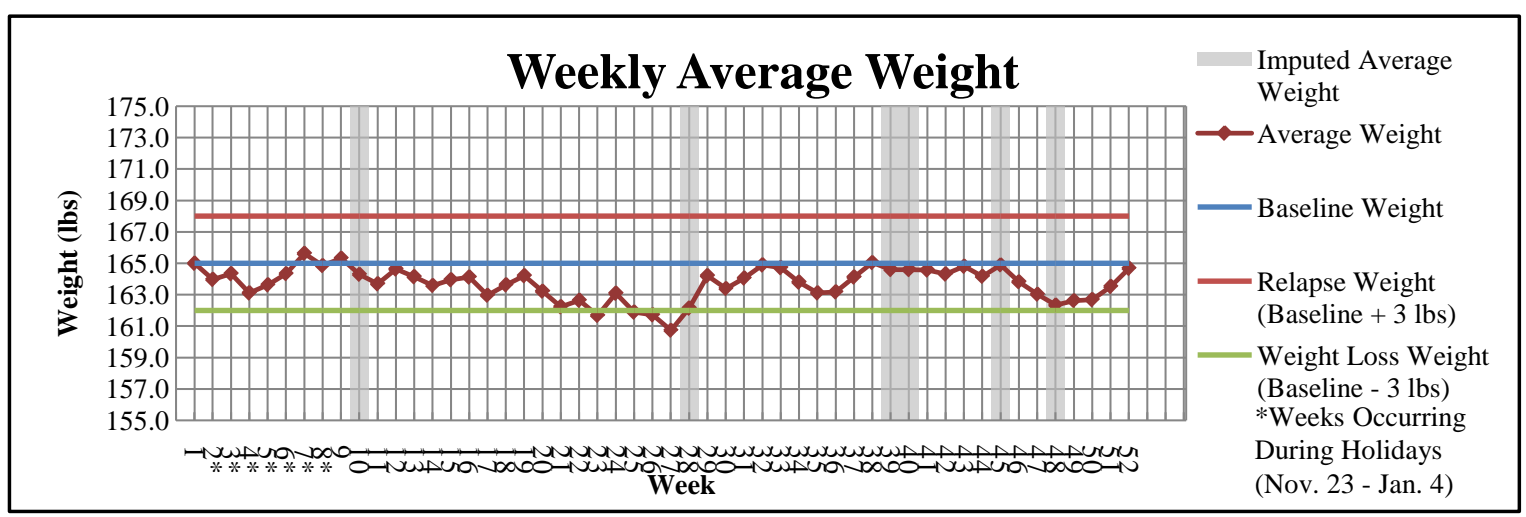



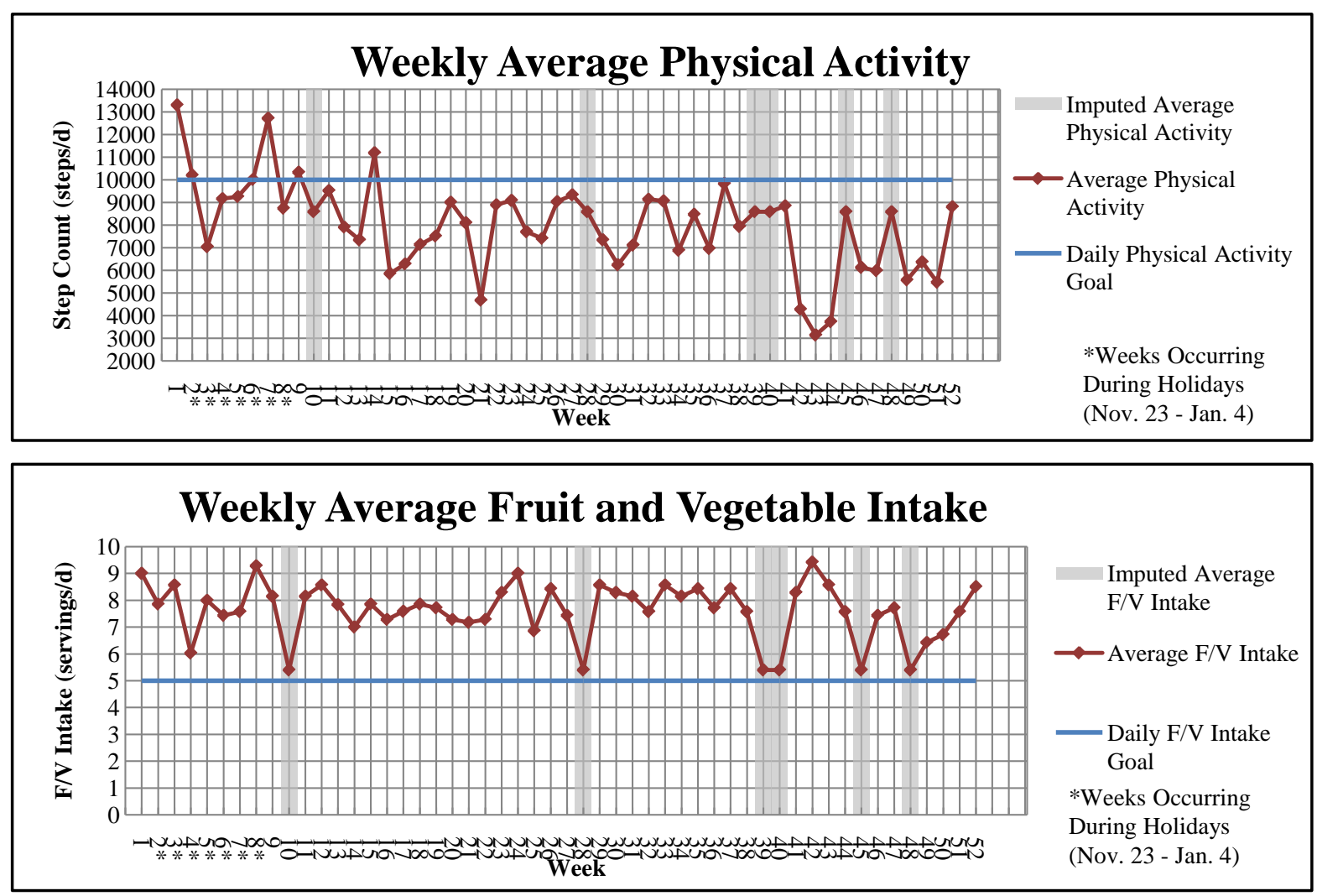

(b)

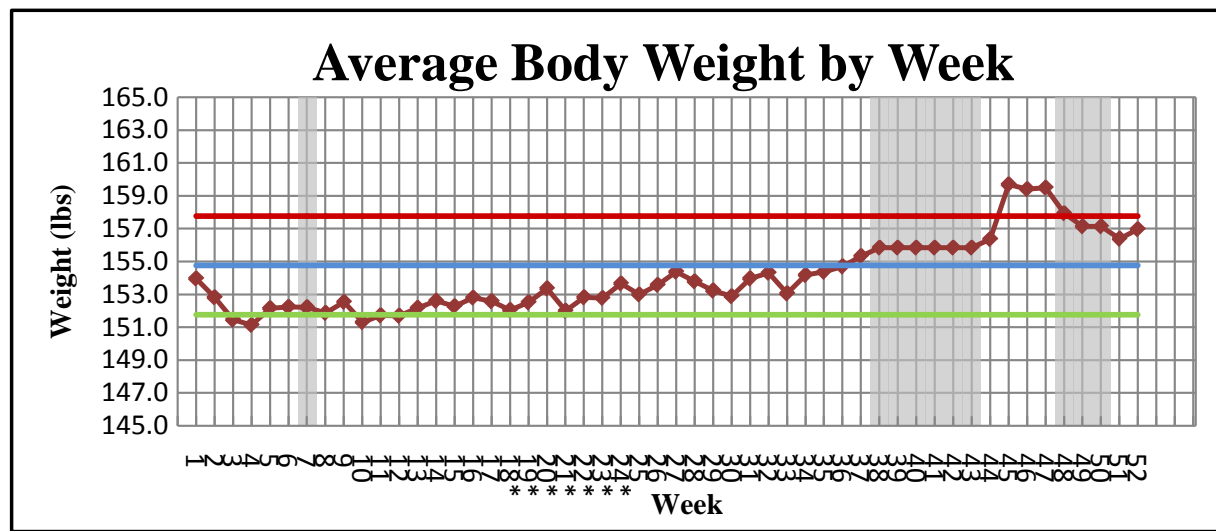

Imputed Average Weight

$\longrightarrow$ Average Weight

——Baseline Weight

- Relapse Weight (Baseline + 3 lbs)

-Weight Loss Weight (Baseline - 3 lbs)

*Weeks Occurring During Holidays

(Nov. 23- Jan. 4)

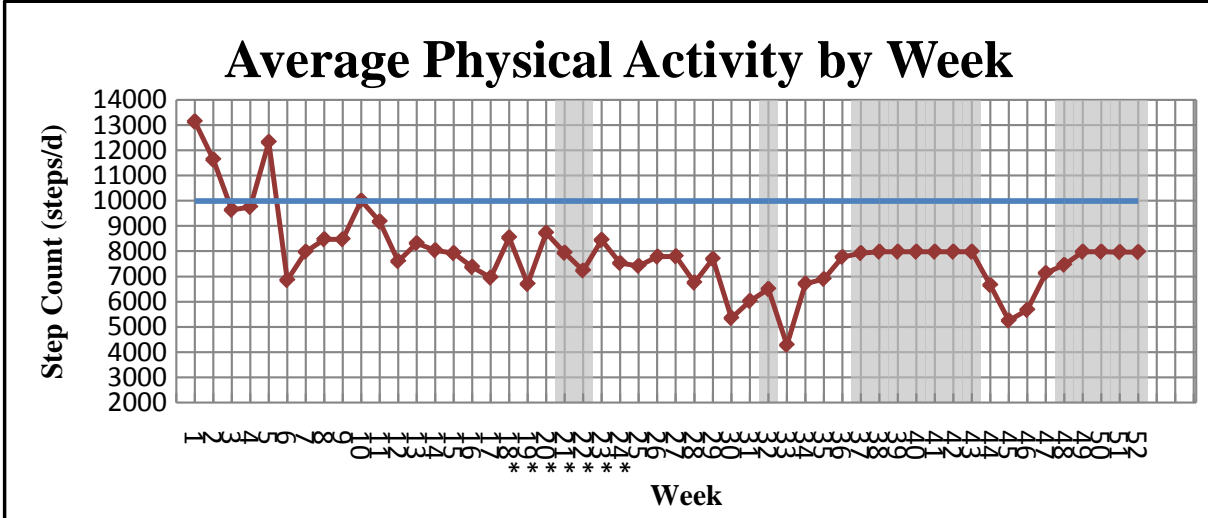

Imputed Average Physical Activity

$\_$Average Physical Activity

Daily Physical Activity Goal

*Weeks Occurring During Holidays (Nov. 23- Jan. 4) 

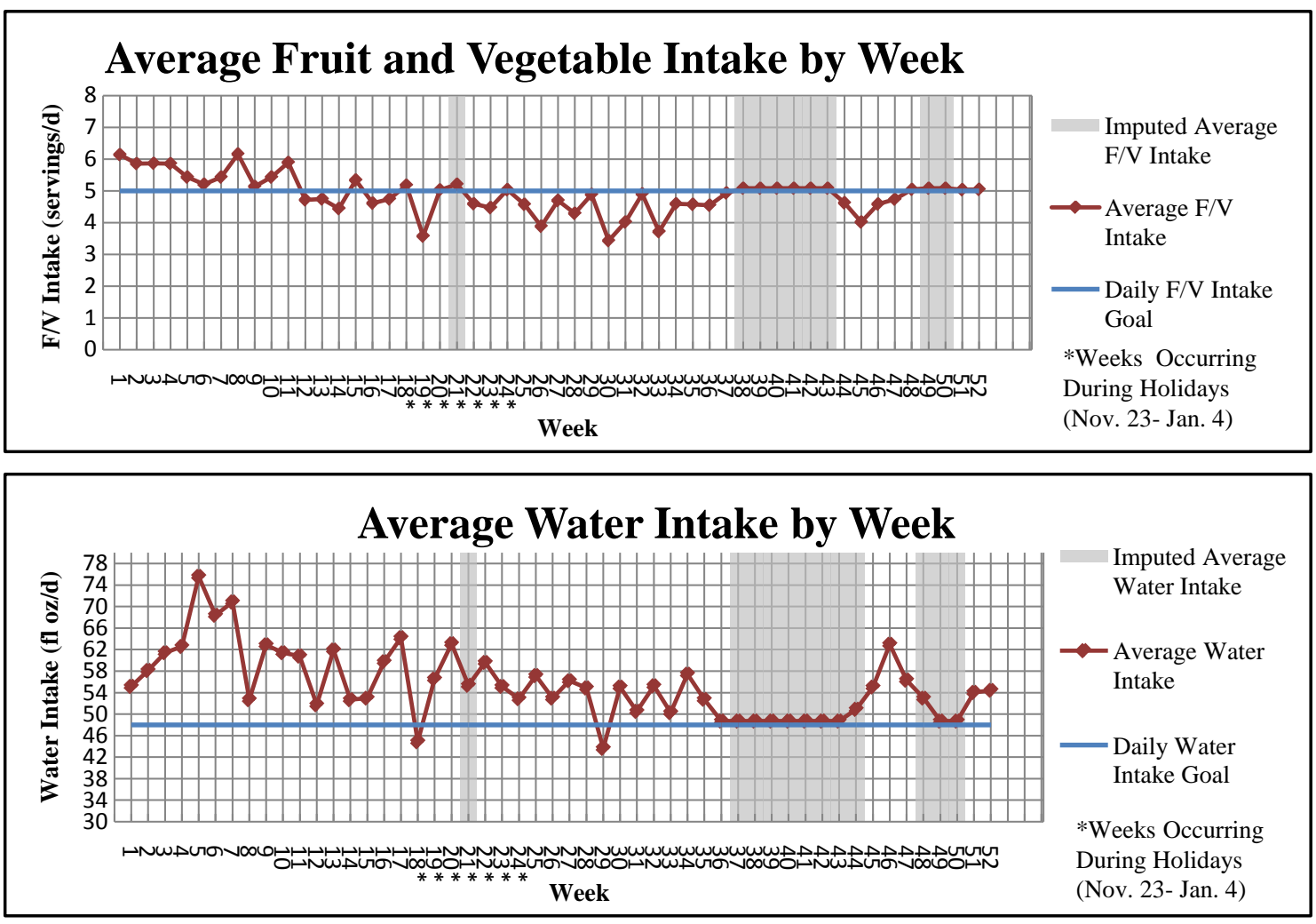

(c)
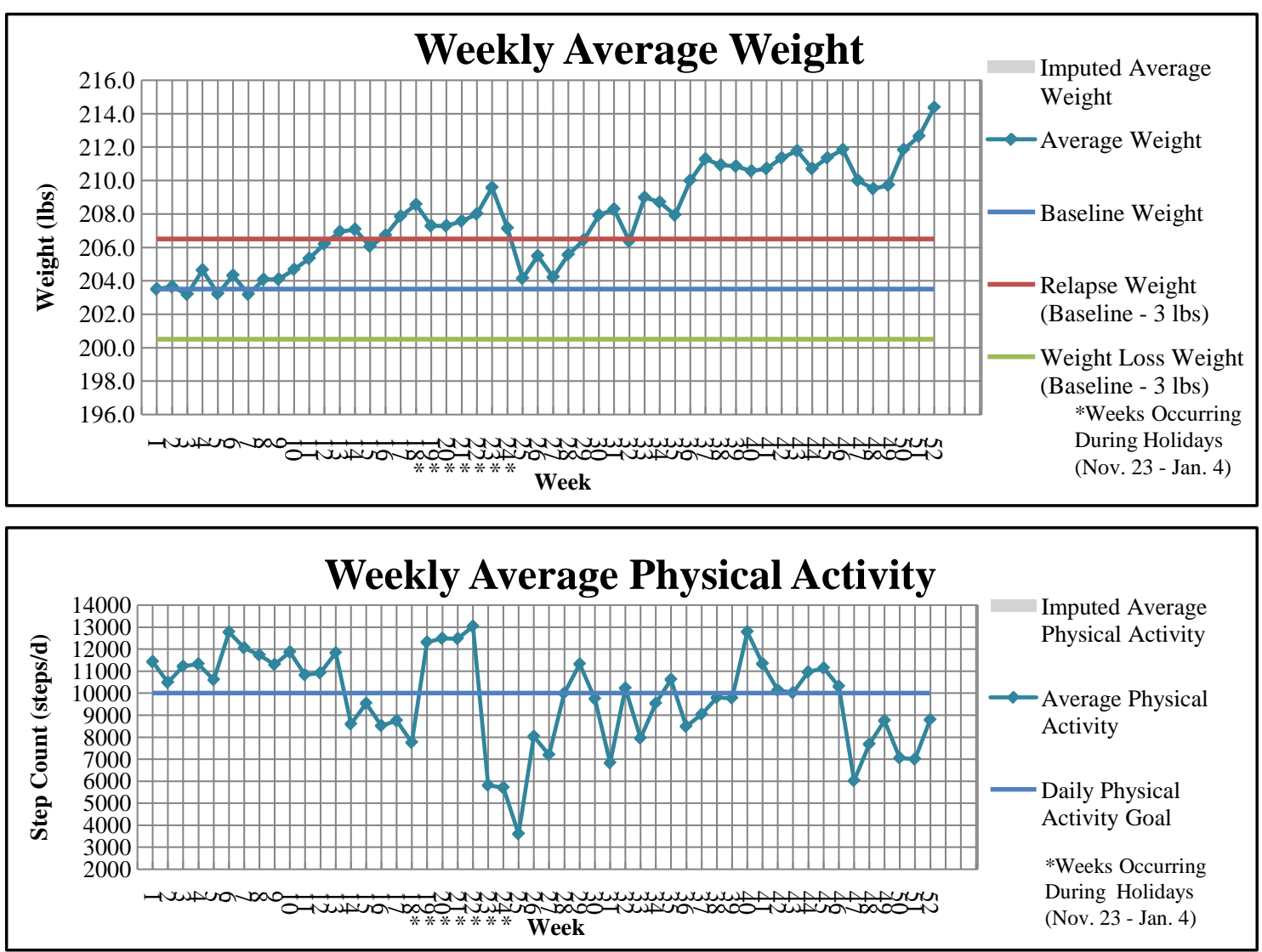


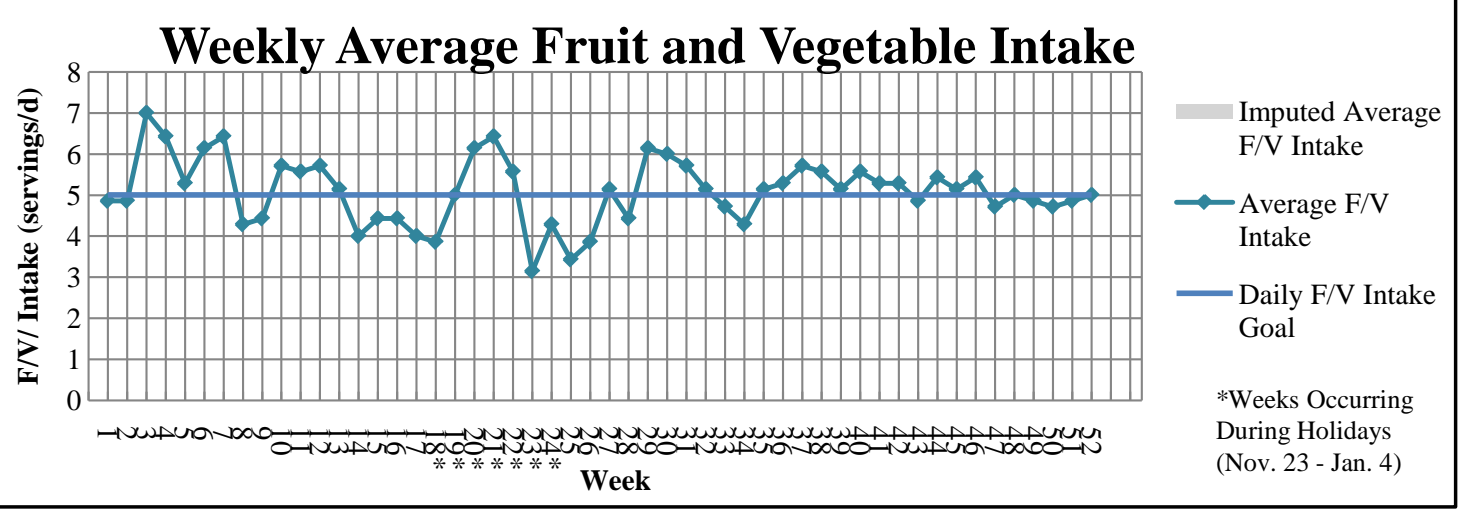

(d)

Figure 1. Representative graphs depicting change in average body weight, physical activity, fruit and vegetable intake, and water intake (for those randomized to a water preload) over 1 year period among participants in the (a) WL group, (b) weight stable group, (c) relapse with recovery group, and (d) relapse without recovery group. Red graphed lines are used for women, and blue graphed lines are used for men. Imputed averages for missing data points are illustrated in gray. Weeks occurring during the holidays (Nov. 23-Jan. 4) are marked with an asterisk ( ${ }^{*}$ ). F/V = fruit and vegetable.

Data were then dichotomously calibrated for each condition based on the specifically defined rules, and results were documented in a truth table. Causal conditions were assessed for weight outcome groups and by sex.

\subsection{Statistical Methods}

Statistical analyses were performed with SPSS. Baseline characteristics for men and women were assessed using independent samples $t$-tests and descriptive statistics. Sex difference in clinically significant WL at 12 months of the WTLM trial was analyzed with Pearson's Chi-squared test, using the criterion of $\geq 5 \%$ total WL, from baseline of the WL trial. A 5\% - 10\% WL in obese patients is associated with reductions in mortality and risk factors for cardiovascular disease and type 2 diabetes [29], and therefore, maintenance of even modest WL would provide important health benefits for most reduced-obese individuals. To assess potential interactions of sex and behavioral predictors of WTLM, a random coefficients (mixed) model (i.e., growth curve analysis) was used because it is able to correct for measurement unreliability and uses individual trajectories to measure change rather than averages [30]. Due to the high variance in daily reported physical activity, log-transformed physical activity was used in the model. Because of the limited sample size, separate growth curve models with bootstrapped standard errors were estimated for the 0 - 6 month and 7 - 11 month time frames.

\section{Results}

The sample was $93 \%$ white, and $43 \%$ were men. Overall, the mean age was $62.7 \pm 5.9$ years, and the mean BMI was $29.3 \pm 4.8 \mathrm{~kg} / \mathrm{m}^{2}$. There were no significant differences between sexes at baseline in age, BMI, or prior percent WL (all >0.05).

\subsection{Qualitative Analysis of Weight Relapse}

Table 1 presents the raw data of the QCA results by weight outcome groups. In the truth table, present conditions are denoted by “ 1 ," and conditions not present are denoted by “ 0 ”.

The QCA for the full sample revealed four conditions considered necessary for successful WTLM overall: 1) adherence to at least one behavioral goal, 2) adherence to the fruit and vegetable intake goal, 3) adherence to the water intake goal, and 4) occurrence of weight gain during the holidays. No two weight outcome groups shared the same pattern of conditions overall. Interestingly, the condition of early first relapse was found to be a necessary and sufficient condition for failure of WTLM. That is, if an individual gained $\geq 3$ lbs during the first 13 weeks of the intervention, he or she was guaranteed to fail at WTLM. Overall, continued WL at 12 weeks and a maximum WL of $\geq 5 \mathrm{lbs}$ from WTLM baseline body weight as a combination of conditions were sufficient for the WL outcome at 12 months. 
Table 1. Qualitative comparative analysis results with four weight outcome groups presented as a truth table.

\begin{tabular}{|c|c|c|c|c|}
\hline \multirow{2}{*}{ Conditions } & \multicolumn{4}{|c|}{ Weight outcome groups } \\
\hline & Weight loss & Weight stable & Relapse with recovery & Relapse without recovery \\
\hline Adherence to $\geq 1$ goal & 1 & 1 & 1 & 1 \\
\hline Adherence to FV goal & 1 & 1 & 1 & 1 \\
\hline Adherence to PA goal & 0 & 0 & 0 & 0 \\
\hline Adherence to water goal & 1 & 1 & 1 & 1 \\
\hline Exceeded $\geq 1$ goal & 0 & 1 & 1 & 1 \\
\hline Exceeded FV goal & 0 & 1 & 0 & 1 \\
\hline Exceeded PA goal & 0 & 0 & 0 & 0 \\
\hline Exceeded water goal & 0 & 1 & 1 & 0 \\
\hline Continued WL through 12 weeks & 1 & 0 & 1 & 0 \\
\hline Weight gain during holidays & 1 & 1 & 1 & 1 \\
\hline First relapse during holidays & 0 & 0 & 0 & 0 \\
\hline Adherence to $\geq 2$ goals & 0 & 0 & 1 & 0 \\
\hline Early first relapse ( $\leq 13$ weeks) & 0 & 0 & 0 & 1 \\
\hline $\begin{array}{l}\geq 5 \text { lbs WL maximum from WTLM baseline } \\
\text { weight (at any point during } 12 \text { months) }\end{array}$ & 1 & 0 & 0 & 0 \\
\hline
\end{tabular}

Conditions present are designated by " 1 ," and conditions not present are designated by "0". WL = weight loss; FV = fruit and vegetable intake; PA = physical activity.

In general, participants categorized in the WL group were adherent to the fruit and vegetable intake goal but did not exceed the goal on average throughout the study. Additionally, they continued to lose weight through the first three months and achieved $\geq 5 \mathrm{lb}$ WL overall (measured from WTLM baseline body weight). Weight stable individuals exceeded at least one behavioral goal, either the fruit and vegetable intake goal or the water goal, and experienced weight gain during the holidays. While some lost weight throughout the study period, particularly during the first three months, the weight stable group on average never lost $\geq 5 \mathrm{lbs}$. In general, the relapse with recovery group exceeded at least one behavioral goal. Women in the group were typically adherent to the fruit and vegetable goal and exceeded the water intake goal, while some men additionally exceeded the physical activity goal. Among the relapse without recovery group, early first relapse and holiday weight gain were notable conditions. Adherence to at least one behavioral goal was also exhibited by individuals in the relapse without recovery group.

Weight outcome groups are divided by sex in Table 2. Only for men in the WL group was holiday weight gain not a necessary condition; for all other sex and outcome group categories, weight gain during the holidays was present. Men in both the relapse with recovery and relapse without recovery groups were adherent to at least two behavioral goals, but this condition was not present in any outcome group for women.

\subsection{Sex Differences in Clinically Significant Weight Loss and Weight Loss Maintenance Behaviors}

Potential physiological predictors, including resting metabolic rate per kg of fat free mass (RMR per kg FFM) and percent body fat measured at baseline, 6, and 12 months, were not included in the growth curve model because no sex differences (all $\mathrm{p}>0.05$ ) were found in these variables during preliminary analyses. Overall RMR per kg FFM and percent body fat have been reported previously [26]. There was no significant sex difference in achieving clinically significant WL $(\geq 5 \% \mathrm{WL})$ at 12 months $\left(\mathrm{X}^{2}=0.123, \mathrm{p}=0.73\right)$. Figure 2(a) depicts the growth curve model with 0 - 12 months, and Figure 2(b) and Figure 2(c) highlight the growth curve models with 0 - 6 months and 7 - 11 months, respectively. In the overall growth curve model, the sex difference in 
Table 2. Qualitative comparative analysis results comparing men and women within four weight outcome groups presented as a truth table.

\begin{tabular}{|c|c|c|c|c|c|c|c|c|}
\hline \multirow{3}{*}{ Conditions } & \multicolumn{8}{|c|}{ Weight outcome groups } \\
\hline & \multicolumn{2}{|c|}{ Weight loss } & \multicolumn{2}{|c|}{ Weight stable } & \multicolumn{2}{|c|}{$\begin{array}{l}\text { Relapse with } \\
\text { recovery }\end{array}$} & \multicolumn{2}{|c|}{$\begin{array}{l}\text { Relapse without } \\
\text { recovery }\end{array}$} \\
\hline & $\begin{array}{l}\text { Men } \\
(n=4)\end{array}$ & $\begin{array}{l}\text { Women } \\
(\mathrm{n}=6)\end{array}$ & $\begin{array}{l}\text { Men } \\
(\mathrm{n}=2)\end{array}$ & $\begin{array}{l}\text { Women } \\
(\mathrm{n}=4)\end{array}$ & $\begin{array}{l}\text { Men } \\
(\mathrm{n}=1)\end{array}$ & $\begin{array}{l}\text { Women } \\
(\mathrm{n}=6)\end{array}$ & $\begin{array}{l}\text { Men } \\
(\mathrm{n}=3)\end{array}$ & $\begin{array}{l}\text { Women } \\
(\mathrm{n}=3)\end{array}$ \\
\hline Adherence to $\geq 1$ goal & 1 & 1 & 1 & 1 & 1 & 1 & 1 & 1 \\
\hline Adherence to FV goal & 1 & 1 & 1 & 0 & 1 & 1 & 1 & 1 \\
\hline Adherence to PA goal & 0 & 0 & 0 & 0 & 1 & 0 & 0 & 0 \\
\hline Adherence to water goal & 1 & 1 & 0 & 1 & 0 & 1 & 1 & 0 \\
\hline Exceeded $\geq 1$ goal & 0 & 0 & 1 & 1 & 1 & 1 & 1 & 0 \\
\hline Exceeded FV goal & 0 & 0 & 1 & 0 & 1 & 0 & 1 & 0 \\
\hline Exceeded PA goal & 0 & 0 & 0 & 0 & 1 & 0 & 0 & 0 \\
\hline Exceeded water goal & 0 & 0 & 0 & 1 & 0 & 1 & 0 & 0 \\
\hline Continued WL through 12 weeks & 1 & 1 & 1 & 0 & 0 & 1 & 0 & 0 \\
\hline Weight gain during holidays & 0 & 1 & 1 & 1 & 1 & 1 & 1 & 1 \\
\hline First relapse during holidays & 0 & 0 & 0 & 0 & 1 & 0 & 0 & 0 \\
\hline Adherence to $\geq 2$ behavior goals & 0 & 0 & 0 & 0 & 1 & 0 & 1 & 0 \\
\hline Early first relapse ( $\leq 13$ weeks) & 0 & 0 & 0 & 0 & 1 & 0 & 1 & 1 \\
\hline $\begin{array}{l}\geq 5 \text { lbs WL maximum from baseline } \\
\text { weight (at any point during } 12 \text { months) }\end{array}$ & 1 & 0 & 0 & 0 & 1 & 0 & 0 & 0 \\
\hline
\end{tabular}

Conditions present are designated by “1,” and conditions not present are designated by “ 0 ”. WL = weight loss; FV = fruit and vegetable intake; PA = physical activity.

weight change was not statistically significant $(\mathrm{p}=0.85$ ). Visual inspection of the growth curve model indicates potential differences in weight change between men and women during months $1,4-6$, and $10-12$ may be present. However, no significant difference was found when the growth curve models were run separately by the two time frames, possibly due to limited statistical power.

\section{Discussion}

The primary finding of the present study was that no significant sex difference in weight change over time was observed; however, there were several important observations from the QCA. The key to WTLM success was evident in the first three months of the intervention. Those who were successful, even despite relapse, continued to lose weight in the first three months of WTLM. This may have allowed them to create a weight "buffer" to prevent excessive, irrecoverable weight gain. In contrast, individuals who failed at overall WTLM, despite efforts to recover (i.e., increasing engagement in behaviors), experienced relapse early in the intervention (within three months). These findings are in agreement with findings from the National Weight Control Registry, which found that few participants recover from even small $(1-2 \mathrm{~kg})$ amounts of weight regain and that preventing large regains from occurring early during WTLM is vital to recovering from relapses that occur later in WTLM [31]. From these findings, it appears that WTLM success at 12 months may be dictated by the patterns of weight change early during WTLM; therefore, the initial weeks of WTLM treatment are likely a "high-risk" period that requires more vigilant efforts in behavior modification to ensure future success.

Furthermore, the WL outcome group was the largest $(n=10)$, suggesting that perhaps personal WL goals had not yet been achieved at the onset of the WTLM trial. These findings are consistent with previous work suggesting that maximum WL is typically achieved by approximately six months of treatment [3]. In addition, individuals who lose more weight early on during WL treatment may sustain WTLM success longer than those who 


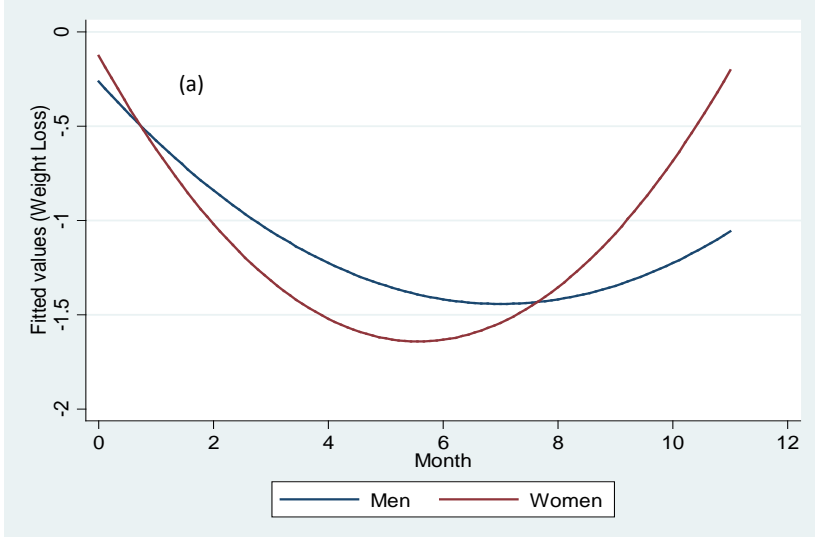

Overall: Weightloss ${ }_{i j}=\beta_{0}+\beta_{1}$ month $_{i j}+\beta_{2}$ month $^{2}$

For Men: Weightoss $\mathrm{ij}_{\mathrm{ij}}=-0.26+-0.34$ month +0.02 month $^{2}$

For Women: Weightloss $\mathrm{ij}_{\mathrm{ij}}=-0.13+-0.54$ month +0.05 month $^{2}$

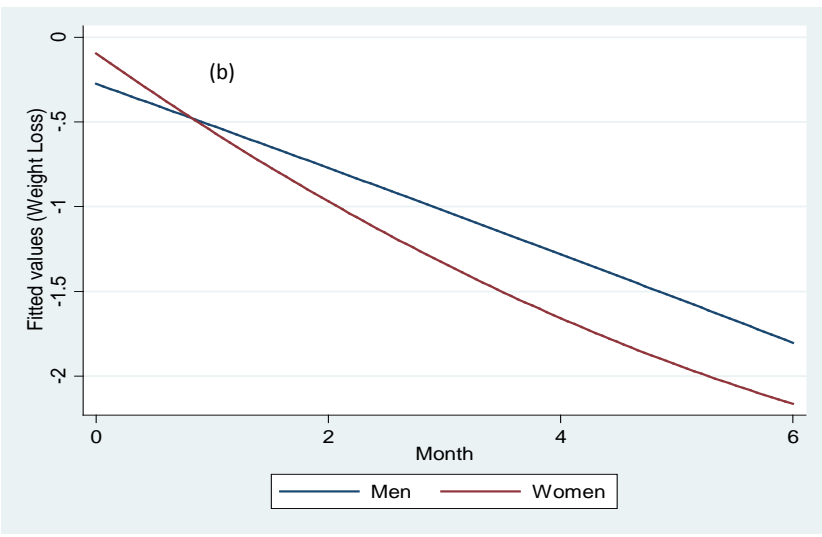

For Men: Weightloss $\mathrm{ij}_{\text {( } 0 \text { to } 6 \text { months) }}=-0.27+-0.25$ month +0.00 month $^{2}$

For Women: Weightloss $\mathrm{ij}_{\mathrm{i}}\left(0\right.$ to 6 months) $=-0.09+-0.48$ month +0.02 month $^{2}$

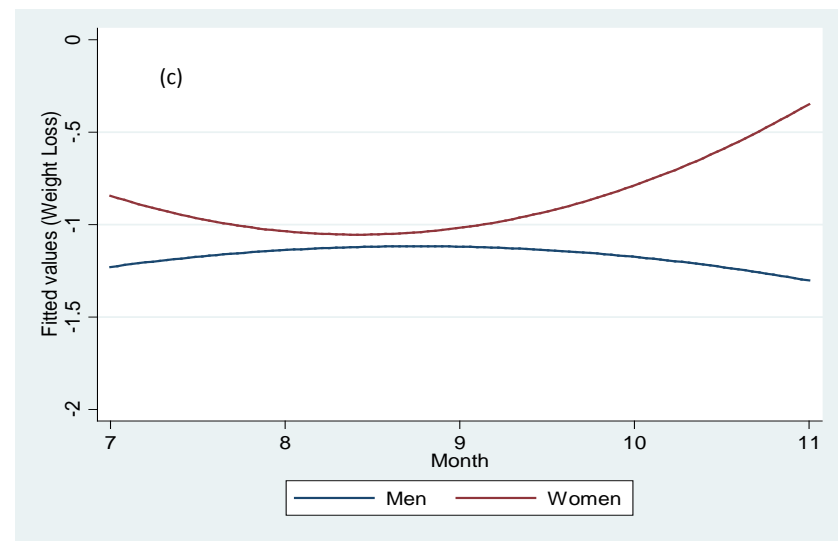

For Men: Weightloss $\mathrm{ij}_{\text {( }} 7$ to 11 months) $=-3.92+0.64$ month +-0.04 month $^{2}$

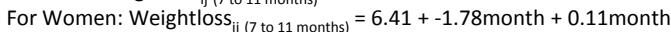

Figure 2. (a) Body weight change according to monthly laboratory body weight measurements for 12 months among men and women, (b) Body weight change estimations with bootstrapped standard errors for 0 - 6 months among men and women, and (c) Body weight change estimations with bootstrapped standard errors for 7 - 11 months among men and women. Equations used for the overall model and estimations with bootstrapped standard errors for 0 - 6 months and 7 - 11 months are shown. 
lose weight more gradually [3]. Thus, more intensive WL treatments lasting at least six months to maximize WL coupled with vigilant weight and behavior monitoring during the transition from WL to WTLM may enhance long-term WTLM success.

Holiday weight gain is common in most individuals attempting WTLM, which is consistent with other reports [32]. Although some amount of weight gain during the holiday period is likely, holiday weight gain in this sample did not affect WTLM outcomes nor relate to irrecoverable relapse. Adherence to the physical activity goal was not found to be a sufficient or necessary condition for WTLM success; this finding is in contrast to extensive data acknowledging physical activity as a principal behavior among individuals successful at WTLM and a potential predictor of success [33]-[36]. It may be that individuals did increase engagement in physical activity compared to baseline amounts, but they may not have been able to meet the 10,000 steps/day goal established by the study investigators and, thus, were considered non-adherent.

The analytic approach used in the present study possesses several unique strengths. First, it utilized individuals who were highly successful overall at WTLM (i.e., 80\% success rate at 12 months) when compared to similar clinical WTLM interventions across the field. Wing and Phelan [31] noted an approximately 20\% success rate at WTLM across studies, when success is defined as maintaining $\geq 10 \% \mathrm{WL}$ for $\geq 1$ year. Second, the WL trial produced similar relative WL results in men and women $(-7.78 \% \pm 0.82 \%$ and $-7.05 \% \pm 0.78 \%$, respectively); thus, both men and women began the WTLM trial with nearly the same reductions in body weight. Third, 17 out of 39 individuals in the WTLM sample were men, a proportion much higher than found in most behavioral interventions, and therefore, comparisons between sexes could be made. Fourth, 12 months of daily selfreported body weight, physical activity, fruit and vegetable intake, and water intake for each individual were available for qualitative analysis of the inter-individual variability in behavior change surrounding weight change.

There are several limitations within this analysis. First, the duration of the study does not permit conclusions to be drawn about WTLM beyond one year. Although self-reported daily body weight was used, self-monitored weights were highly correlated with monthly body weights measured in laboratory assessments $(r=0.99$, p $<$ 0.001). Finally, the small sample size is a limitation, but the qualitative analysis of individual data for a full 365-day study period is a unique approach providing useful information for those interested in designing largerscale trials of WTLM.

\section{Conclusion}

In summary, sex differences in weight change or total WL outcomes were not observed in the present analysis. However, the results of our study suggest that men and women may approach WTLM with different behaviors. Further research to identify predictors of successful WTLM, particularly pretreatment factors (including sex), is essential to determine appropriate WTLM treatment strategies for an individualized approach. In current practice, intensive WL treatment lasting at least six months should be used to maximize initial WL, and concerted effort should be made during the transition period from WL to WTLM to vigilantly monitor weight to prevent large, early weight regains, which can sabotage future WTLM success. Additionally, WTLM treatment programs should implement the concept of individualized treatment in current practice, even though research has not determined all factors predicting success, and should focus on autonomy and flexibility in treatment strategies to match individuals’ preferences with treatment characteristics.

\section{References}

[1] Finkelstein, E.A., Trogdon, J.G., Cohen, J.W. and Dietz, W. (2009) Annual Medical Spending Attributable to Obesity: Payer- and Service-Specific Estimates. Health Affairs (Millwood), 28, w822-w831. http://dx.doi.org/10.1377/hlthaff.28.5.w822

[2] Wadden, T.A., Berkowitz, R.I., Womble, L.G., Sarwer, D.B., Phelan, S., Cato, R.K., Hesson, L.A., Osei, S.Y., Kaplan, R. and Stunkard, A.J. (2005) Randomized Trial of Lifestyle Modification and Pharmacotherapy for Obesity. The New England Journal of Medicine, 353, 2111-2120. http://dx.doi.org/10.1056/NEJMoa050156

[3] Jeffery, R.W., Drewnowski, A., Epstein, L.H., Stunkard, A.J., Wilson, G.T., Wing, R.R. and Hill, D.R. (2000) LongTerm Maintenance of Weight Loss: Current Status. Health Psychology, 19, 5-16. http://dx.doi.org/10.1037/0278-6133.19.Suppl1.5

[4] Elfhag, K. and Rossner, S. (2005) Who Succeeds in Maintaining Weight Loss? A Conceptual Review of Factors Associated with Weight Loss Maintenance and Weight Regain. Obesity Reviews: An Official Journal of the International Association for the Study of Obesity, 6, 67-85. http://dx.doi.org/10.1111/j.1467-789X.2005.00170.x 
[5] Wadden, T.A., Butryn, M.L. and Wilson, C. (2007) Lifestyle Modification for the Management of Obesity. Gastroenterology, 132, 2226-2238. http://dx.doi.org/10.1053/j.gastro.2007.03.051

[6] Wing, R.R., Tate, D.F., Gorin, A.A., Raynor, H.A. and Fava, J.L. (2006) A Self-Regulation Program for Maintenance of Weight Loss. The New England Journal of Medicine, 355, 1563-1571. http://dx.doi.org/10.1056/NEJMoa061883

[7] Befort, C.A., Stewart, E.E., Smith, B.K., Gibson, C.A., Sullivan, D.K. and Donnelly, J.E. (2008) Weight Maintenance, Behaviors and Barriers among Previous Participants of a University-Based Weight Control Program. International Journal of Obesity (London), 32, 519-526. http://dx.doi.org/10.1038/sj.ijo.0803769

[8] McGuire, M.T., Wing, R.R., Klem, M.L., Lang, W. and Hill, J.O. (1999) What Predicts Weight Regain in a Group of Successful Weight Losers? Journal of Consulting and Clinical Psychology, 67, 177-185. http://dx.doi.org/10.1037/0022-006X.67.2.177

[9] Klem, M.L., Wing, R.R., Lang, W., McGuire, M.T. and Hill, J.O. (2000) Does Weight Loss Maintenance Become Easier Over Time? Obesity Research, 8, 438-444. http://dx.doi.org/10.1038/oby.2000.54

[10] Svetkey, L.P., Stevens, V.J., Brantley, P.J., Appel, L.J., Hollis, J.F., Loria, C.M., Vollmer, W.M., Gullion, C.M., Funk, K., Smith, P., et al. (2008) Comparison of Strategies for Sustaining Weight Loss: The Weight Loss Maintenance Randomized Controlled Trial. JAMA: The Journal of the American Medical Association, 299, 1139-1148. http://dx.doi.org/10.1001/jama.299.10.1139

[11] McGuire, M.T., Wing, R.R., Klem, M.L., Seagle, H.M. and Hill, J.O. (1998) Long-Term Maintenance of Weight Loss: Do People Who Lose Weight through Various Weight Loss Methods Use Different Behaviors to Maintain Their Weight? International Journal of Obesity and Related Metabolic Disorders: Journal of the International Association for the Study of Obesity, 22, 572-577. http://dx.doi.org/10.1038/sj.ijo.0800627

[12] Butryn, M.L., Phelan, S., Hill, J.O. and Wing, R.R. (2007) Consistent Self-Monitoring of Weight: A Key Component of Successful Weight Loss Maintenance. Obesity (Silver Spring), 15, 3091-3096. http://dx.doi.org/10.1038/oby.2007.368

[13] Muckelbauer, R., Sarganas, G., Gruneis, A. and Muller-Nordhorn, J. (2013) Association between Water Consumption and Body Weight Outcomes: A Systematic Review. The American Journal of Clinical Nutrition, 98, 282-299. http://dx.doi.org/10.3945/ajcn.112.055061

[14] Dennis, E.A., Flack, K.D. and Davy, B.M. (2009) Beverage Consumption and Adult Weight Management: A Review. Eating Behaviors, 10, 237-246. http://dx.doi.org/10.1016/j.eatbeh.2009.07.006

[15] Ogden, L.G., Stroebele, N., Wyatt, H.R., Catenacci, V.A., Peters, J.C., Stuht, J., Wing, R.R. and Hill, J.O. (2012) Cluster Analysis of the National Weight Control Registry to Identify Distinct Subgroups Maintaining Successful Weight Loss. Obesity (Silver Spring), 20, 2039-2047. http://dx.doi.org/10.1038/oby.2012.79

[16] Melanson, E.L., Keadle, S.K., Donnelly, J.E., Braun, B. and King, N.A. (2013) Resistance to Exercise-Induced Weight Loss: Compensatory Behavioral Adaptations. Medicine and Science in Sports and Exercise, 45, 1600-1609. http://dx.doi.org/10.1249/MSS.0b013e31828ba942

[17] Forster, J.L. and Jeffery, R.W. (1986) Gender Differences Related to Weight History, Eating Patterns, Efficacy Expectations, Self-Esteem, and Weight Loss among Participants in a Weight Reduction Program. Addictive Behaviors, 11, 141-147. http://dx.doi.org/10.1016/0306-4603(86)90039-0

[18] Lovejoy, J.C. and Sainsbury, A. (2009) Sex Differences in Obesity and the Regulation of Energy Homeostasis. Obesity Reviews: An official Journal of the International Association for the Study of Obesity, 10, 154-167.

[19] Pagoto, S.L., Schneider, K.L., Oleski, J.L., Luciani, J.M., Bodenlos, J.S. and Whited, M.C. (2012) Male Inclusion in Randomized Controlled Trials of Lifestyle Weight Loss Interventions. Obesity (Silver Spring), 20, 1234-1239. http://dx.doi.org/10.1038/oby.2011.140

[20] Hagobian, T.A., Sharoff, C.G., Stephens, B.R., Wade, G.N., Silva, J.E., Chipkin, S.R. and Braun, B. (2009) Effects of Exercise on Energy-Regulating Hormones and Appetite in Men and Women. American Journal of Physiology-Regulatory, Integrative and Comparative Physiology, 296, R233-R242. http://dx.doi.org/10.1152/ajpregu.90671.2008

[21] Hagobian, T.A. and Braun, B. (2010) Physical Activity and Hormonal Regulation of Appetite: Sex Differences and Weight Control. Exercise and Sport Sciences Reviews, 38, 25-30. http://dx.doi.org/10.1097/JES.0b013e3181c5cd98

[22] Davy, B.M., Van Walleghen, E.L. and Orr, J.S. (2007) Sex Differences in Acute Energy Intake Regulation. Appetite, 49, 141-147. http://dx.doi.org/10.1016/j.appet.2007.01.010

[23] Appelhans, B.M., Whited, M.C., Schneider, K.L. and Pagoto, S.L. (2011) Time to Abandon the Notion of Personal Choice in Dietary Counseling for Obesity? Journal of the American Dietetic Association, 111, 1130-1136. http://dx.doi.org/10.1016/j.jada.2011.05.014

[24] Wang, W.C., Worsley, A. and Hunter, W. (2012) Similar but Different. Health Behaviour Pathways Differ between Men and Women. Appetite, 58, 760-766. http://dx.doi.org/10.1016/j.appet.2012.01.008 
[25] Dennis, E.A., Dengo, A.L., Comber, D.L., Flack, K.D., Savla, J., Davy, K.P. and Davy, B.M. (2010) Water Consumption Increases Weight Loss during a Hypocaloric Diet Intervention in Middle-Aged and Older Adults. Obesity (Silver Spring), 18, 300-307. http://dx.doi.org/10.1038/oby.2009.235

[26] Akers, J.D., Cornett, R.A., Savla, J.S., Davy, K.P. and Davy, B.M. (2012) Daily Self-Monitoring of Body Weight, Step Count, Fruit/Vegetable Intake, and Water Consumption: A Feasible and Effective Long-Term Weight Loss Maintenance Approach. Journal of the Academy of Nutrition and Dietetics, 112, 685-692.

[27] IBM (2011) IBM SPSS Missing Values 20. IBM Corporation.

[28] Kahwati, L.C., Lewis, M.A., Kane, H., Williams, P.A., Nerz, P., Jones, K.R., Lance, T.X., Vaisey, S. and Kinsinger, L.S. (2011) Best Practices in the Veterans Health Administration's MOVE! Weight Management Program. American Journal of Preventive Medicine, 41, 457-464. http://dx.doi.org/10.1016/j.amepre.2011.06.047

[29] Goldstein, D.J. (1992) Beneficial Health Effects of Modest Weight Loss. International Journal of Obesity and Related Metabolic Disorders: Journal of the International Association for the Study of Obesity, 16, 397-415.

[30] Singer, J.W.J. (2003) Applied Longitudinal Data Analysis: Modeling Change and Event Occurrence. Oxford University Press, New York. http://dx.doi.org/10.1093/acprof:oso/9780195152968.001.0001

[31] Wing, R.R. and Phelan, S. (2005) Long-Term Weight Loss Maintenance. The American Journal of Clinical Nutrition, 82, 222S-225S.

[32] Yanovski, J.A., Yanovski, S.Z., Sovik, K.N., Nguyen, T.T., O’Neil, P.M. and Sebring, N.G. (2000) A Prospective Study of Holiday Weight Gain. The New England Journal of Medicine, 342, 861-867. http://dx.doi.org/10.1056/NEJM200003233421206

[33] Klem, M.L., Wing, R.R., McGuire, M.T., Seagle, H.M. and Hill, J.O. (1997) A Descriptive Study of Individuals Successful at Long-Term Maintenance of Substantial Weight Loss. The American Journal of Clinical Nutrition, 66, 239246.

[34] Catenacci, V.A., Grunwald, G.K., Ingebrigtsen, J.P., Jakicic, J.M., McDermott, M.D., Phelan, S., Wing, R.R., Hill, J.O. and Wyatt, H.R. (2011) Physical Activity Patterns Using Accelerometry in the National Weight Control Registry. Obesity (Silver Spring), 19, 1163-1170. http://dx.doi.org/10.1038/oby.2010.264

[35] Jakicic, J.M. (2009) The Effect of Physical Activity on Body Weight. Obesity (Silver Spring), 17, S34-S38. http://dx.doi.org/10.1038/oby.2009.386

[36] Phelan, S., Roberts, M., Lang, W. and Wing, R.R. (2007) Empirical Evaluation of Physical Activity Recommendations for Weight Control in Women. Medicine and Science in Sports and Exercise, 39, 1832-1836. http://dx.doi.org/10.1249/mss.0b013e31812383c3 